\title{
Intertwining extracorporeal membrane oxygenation and continuous renal replacement therapy: sense or nonsense?
}

\author{
Rita Jacobs, Patrick M Honore* and Herbert D Spapen \\ See related research by Chen et al., http://ccforum.com/content/18/6/675
}

We would like to comment on the excellent review by Chen and colleagues highlighting the safety and efficacy of combining extracorporeal membrane oxygenation (ECMO) and continuous renal replacement therapy (CRRT) for fluid and electrolyte control [1].

As a high-flow system equipped with heparin-coated membranes and circuits, ECMO requires no or only minimal additional anticoagulation to assure circuit patency $[2,3]$. In contrast, CRRT essentially remains a low-flow system that demands specific anticoagulation to avoid early circuit clotting $[2,3]$. Thus, creating a two-in-one ECMO/CRRT system will have evident limitations and drawbacks. The introduction of a hemofiltration filter inside the ECMO circuit renders ultrafiltrate volume removal inaccurate and prohibits pressure monitoring in the circuit, thereby reducing the filter lifespan. Embedding a full CRRT device in series with an ECMO circuit may obviate these shortcomings. However, the dramatic difference in flow and pressure will increase shear stress, activate the clotting cascade and release noxious cytokines, which exposes patients to the potential life-threatening effects of hemolysis, disseminated intravascular coagulation and enhanced systemic inflammation [4,5]. Moreover, a hemolysis-induced excessive rise of plasma-free hemoglobin and subsequent hemoglobinuria adversely affects renal tubular function and may induce or exacerbate acute kidney injury $[4,5]$.
For these reasons, we strongly argue against the combined use of ECMO and CRRT within a single circuit. In addition, a separate CRRT device can perfectly run under a proper dedicated anticoagulation therapy (for example, regional citrate). This permits avoidance of ECMO-induced anticoagulant dilution, resulting in less thrombotic events [2].

\section{Abbreviations \\ CRRT: Continuous renal replacement therapy; ECMO: Extracorporeal membrane oxygenation.}

\section{Competing interests}

The authors declare that they have no competing interests.

\section{Authors' contributions}

$\mathrm{RJ}, \mathrm{PMH}$ and HDS designed and wrote the paper. All authors read and approved the final manuscript.

Published online: 25 March 2015

\section{References}

1. Chen H, Yu RG, Yin NN, Zhou JX. Combination of extracorporeal membrane oxygenation and continuous renal replacement therapy in critically ill patients: a systemic review. Crit Care. 2014;18:675.

2. Jacobs R, Honore PM, De Regt J, de Mars M, Spapen HS. Citrate during CRRT \& ECMO. In: Vuylsteke A, series editor. Renal replacement therapy - core critical care. Cambridge University Press; 2015, in press.

3. McMullan DM, Emmert JA, Permut LC, Mazor RL, Jeffries HE, Parrish AR, et al. Minimizing bleeding associated with mechanical circulatory support following pediatric heart surgery. Eur J Cardiothorac Surg. 2011;39:392-7.

4. Gbadegesin R, Zhao S, Charpie J, Brophy PD, Smoyer WE, Lin J. Significance of hemolysis on extracorporeal life support after cardiac surgery in children. J Pediatr Nephrol. 2009;24:589-95.

5. Bertrus C, Remenapp R, Charpie J, Kudelka T, Brophy P, Smoyer WE, et al. Enhanced hemolysis in pediatric patients requiring extracorporeal membrane oxygenation and continuous renal replacement therapy. Ann Thorac Cardiovas Surg. 2007;13:378-83.

\footnotetext{
* Correspondence: Patrick.Honore@uzbrussel.be

ICU Department, UZ Brussel, VUB University, 101 Laarbeeklaan, 1090 Jette, Brussels, Belgium
}

\section{Biomed Central}

(c) 2015 Jacobs et al.; licensee BioMed Central. This is an Open Access article distributed under the terms of the Creative Commons Attribution License (http://creativecommons.org/licenses/by/4.0), which permits unrestricted use, distribution, and reproduction in any medium, provided the original work is properly credited. The Creative Commons Public Domain Dedication waiver (http://creativecommons.org/publicdomain/zero/1.0/) applies to the data made available in this article, unless otherwise stated. 